\title{
The Ketamine Model of the Near-Death Experience: A Central Role for the N-Methyl-D-Aspartate Receptor
}

\author{
Karl L. R. Jansen, M.D., Ph.D., M.R.C.Psych. \\ The Maudsley Hospital, London, United Kingdom
}

\begin{abstract}
Near-death experiences (NDEs) can be reproduced by ketamine via blockade of receptors in the brain for the neurotransmitter glutamate, the N-methyl-D-aspartate (NMDA) receptors. Conditions that precipitate NDEs, such as hypoxia, ischemia, hypoglycemia, and temporal lobe epilepsy, have been shown to release a flood of glutamate, overactivating NMDA receptors and resulting in neurotoxicity. Ketamine prevents this neurotoxicity. There are substances in the brain that bind to the same receptor site as ketamine. Conditions that trigger a glutamate flood may also trigger a flood of neuroprotective agents that bind to NMDA receptors to protect cells, leading to an altered state of consciousness like that produced by ketamine.
\end{abstract}

The near-death experience (NDE) is a phenomenon of considerable importance to medicine, neuroscience, neurology, and psychiatry (Greyson and Stevenson, 1980; Jansen, 1989a, 1989b, 1990b; Ring, 1980; Sabom, 1982; Stevenson and Greyson, 1979). Recent advances in neuroscience are bringing us closer to a scientific understanding of this intriguing altered state of consciousness. Irrespective of personal religious and philosophical beliefs, NDEs are not evidence for life after death on simple logical grounds: death is defined as the final, irreversible end. The Oxford English Dictionary (Sykes, 1982) refers to death as the "final cessation of vital functions" (italics added). Those who have "returned" did not, by definition, die, al-

Karl L. R. Jansen, M.D., Ph.D., M.R.C.Psych., is a psychiatrist at the Maudsley Hospital. Reprint requests should be addressed to Dr. Jansen at the Maudsley Hospital, Denmark Hill, London SE5 8AZ, United Kingdom. 
though their minds, brains, and bodies may have been in a very unusual state. The theory developed in this paper makes no attempt to address religious beliefs about events after death, but does argue that persons who report NDEs have not died.

There is overwhelming evidence from thousands of studies relating brain events to alterations in mental state that "mind" results from neuronal activity. The dramatic effects on the mind of adding hallucinogenic drugs to the brain, and the religious experiences that sometimes result, provide further evidence for this (Grinspoon and Bakalar, 1979). Within a scientific paradigm, it is not possible that the "spirit rises out of the body, leaving the brain behind, but somehow still incorporating neuronal functions such as sight, hearing, and proprioception" (Morse, 1989, p. 225).

Features that have been associated with NDEs can be reproduced by the intravenous administration of 50 to 100 milligrams of ketamine (Collier, 1972; Domino, Chodoff, and Corssen, 1965; Ghoneim, Hinrichs, Mewaldt, and Peterson, 1985; Grinspoon and Bakalar, 1979; Jansen, 1989a, 1989b, 1990b, 1993; Lilly, 1978; Rogo, 1984; Rumpf, Pedick, Teuteberg, Munchhoff, and Nolte, 1969; Siegel, 1978, 1980, 1981; Sputz, 1989; Stafford, 1977; White, Way, and Trevor, 1982). There is increasing evidence suggesting that the reproduction of NDEs by ketamine is unlikely to be a coincidence. This evidence includes the discovery of the major neuronal binding site for ketamine, known as the phencyclidine (PCP) binding site of the $\mathrm{N}$-methyl-D-aspartate (NMDA) receptor (Thomson, West, and Lodge, 1985); the importance of NMDA receptors in the cerebral cortex, particularly in the temporal and frontal lobes; the key role of these sites in cognitive processing, memory, and perception; their role in epilepsy, psychoses (Jansen and Faull, 1991), hypoxia/ischemia, and epileptic cell damage (excitotoxicity); the prevention of this damage by ketamine; the discovery of substances in the brain called "endopsychosins," which bind to the same site as ketamine; and the role of ions such as magnesium and zinc in regulating the site (Anis, Berry, Burton, and Lodge, 1983; Barnes, 1988; Ben-Ari, 1985; Benveniste, Drejer, Schousboe, and Diemer, 1984; Choi, 1988; Coan and Collingridge, 1987; Collingridge, 1987; Contreras, DiMaggio, and O'Donohue, 1987; Cotman and Monaghan, 1987; Jansen, 1989a, 1989b, 1990a, 1990b, 1991, 1993; Jansen and Faull, 1991; Jansen, Faull, and Dragunow, 1989; Jansen, Faull, Dragunow, and Leslie, 1991; Jansen, Faull, Dragunow, and Synek, 1990; Mody and Heinemann, 1987; Monaghan, Bridges, and Cotman, 1989; Nowak, Ber- 
gestovski, Ascher, Herbet, and Prochiantz, 1987; Quirion, Chicheportiche, Contreras, Johnston, Lodge, Tam, Woods, and Zukin, 1987; Quirion, DiMaggio, French, Contreras, Shiloach, Pert, Everist, Pert, and O'Donohue, 1984; Rothman and Olney, 1987; Simon, Swan, Griffiths, and Meldrum, 1984; Sonders, Keana, and Weber, 1988; Thomson, 1986; Westbrook and Mayer, 1987).

\section{Characteristic Features of the Near-Death Experience}

There is no internationally determined and agreed upon set of criteria that define the NDE, no list of "research diagnostic criteria" similar to those provided by the American Psychiatric Association (APA) for psychiatric disorders. This lack has allowed some critics of neurobiological models to dismiss those models because some particular criterion they consider important was not fully accounted for by the model being proposed, although it may well be that a consensus, statistical definition of the key features of the NDE would not include those features-just as, for example, the APA definition of schizophrenia (American Psychiatric Association, 1994) represents an international consensus and avoids the sectarian views of a few, or inclusion of obscure cases that do not meet the general rule.

For example, Glen Gabbard and Stuart Twemlow (1989) argued that Juan Saavedra-Aguilar and Juan Gómez-Jeria's neurobiological hypothesis (1989), which was based on temporal lobe electrical abnormalities, did not have general validity because Gabbard and Twemlow had identified five cases in which hypoxia and stress did not appear to be a triggering factor. These cases are certainly not adequate grounds for the dismissal of neurobiological models.

Ketamine administered by intravenous injection in appropriate dosage can reproduce all the features of the NDE that have been commonly described in the most cited works in this field (Collier, 1972; Domino, Chodoff, and Corssen, 1965; Ghoneim, Hinrichs, Mewaldt, and Peterson, 1985; Grinspoon and Bakalar, 1979; Jansen, 1989a, 1989b, 1990b, 1991, 1993; Lilly, 1978; Rogo, 1984; Rumpf, Pedick, Teuteberg, Munchhoff, and Nolte, 1969; Siegel, 1978, 1980, 1981; Sputz, 1989; Stafford, 1977; White, Way, and Trevor, 1982), and the account outlined below is based upon these works and also upon NDEs described to me. Unfortunately, the study in which persons who have had NDEs are given ketamine and asked to compare the 
two experiences has yet to be carried out. Information in this area remains anecdotal.

I have experienced several NDEs and have also been administered ketamine as an anesthetic and within experimental paradigms. The NDEs and the ketamine experiences were very similar. Ketamine produced effects that were like the NDEs described by Bruce Greyson and Ian Stevenson (1980), by Melvin Morse, Doug Conner, and Donald Tyler (1985), by Raymond Moody (1975), by Russell Noyes and Roy Kletti (1976a), by Kenneth Ring (1980), and by Michael Sabom (1982). Ketamine produced travel through a tunnel, emergence into the light, and a "telepathic" exchange with an entity that could be described as "God," although I have no religious beliefs and had no particular expectations on first experiencing the drug. Neither the NDEs nor the ketamine experiences bore any resemblance to the effects of psychedelic drugs such as dimethyltryptamine (DMT) and lysergic acid diethylamide (LSD), in contradistinction to a previous assertion by Scott Rogo that ketamine "induces a short psychedelic 'trip' resembling that induced by lysergic acid diethylamide (LSD)" (1984, p. 88).

Important features of NDEs include a sense that what is experienced is "real" and that one is actually dead, a sense of ineffability, timelessness, and feelings of calm and peace, although some cases have been frightening. There may be analgesia, apparent clarity of thought, a perception of separation from the body, and hallucinations of landscapes and beings such as "angels" or people, including partners, parents, teachers and friends (who may be alive at the time), and religious and mythical figures. Transcendent mystical states are commonly described. Memories may emerge into consciousness, and are sometimes organized into a "life review" (Greyson, 1983). Hearing noises during the initial part of the NDE has also been described (Greyson and Stevenson, 1980; Morse, Conner, and Tyler, 1985; Noyes and Kletti, 1976a; Osis and Haraldsson, 1977; Ring, 1980; Sabom, 1982).

Kenneth Ring (1980) classified NDEs on a five-stage continuum: (1) feelings of peace and contentment; (2) a sense of detachment from the body; (3) entering a transitional world of darkness (the "tunnel experience"); (4) seeing a bright light; and (5) "entering the light." Sixty percent of NDErs interviewed by Ring experienced stage 1, but only 10 percent attained stage 5 (Ring, 1980). As might be expected in a mental state with a neurobiological origin, more mundane accounts also occur, such as children who may "see" their schoolfellows rather than God and angels (Morse, Conner, and Tyler, 1985). 


\section{Ketamine and Phencyclidine}

Ketamine, first synthesized in 1962 by Calvin Stevens (McCarthy, 1981), is a short-acting, hallucinogenic, dissociative anesthetic related to phencyclidine (PCP). Both ketamine and PCP are arylcyclohexylamines; they are not opioids and are not related to LSD. In contrast to PCP, ketamine is relatively safe, an uncontrolled drug in most countries, and is used as an anesthetic for children (White, Way, and Trevor, 1982). Anesthetists attempt to prevent patients from having NDEs or "emergence phenomena" by the co-administration of benzodiazepines and other sedative substances that produce "true" unconsciousness rather than dissociation (Reich and Silvay, 1989).

Ketamine produces an altered state of consciousness that is very different from that of "psychedelic" drugs such as LSD (Grinspoon and Bakalar, 1979). As noted in the references cited above, it can reproduce all features of the NDE, including travel through a dark tunnel into light, the conviction that one is dead, apparent "telepathic communion with God," hallucinations, out of-body experiences, and mystical states. If given intravenously, it has a brief action with an abrupt end. Lester Grinspoon and James Bakalar wrote of

becoming a disembodied mind or soul, dying and going to another world. Childhood events may also be re-lived. The loss of contact with ordinary reality and the sense of participation in another reality are more pronounced and less easily resisted than is usually the case with LSD. The dissociative experiences often seem so genuine that users are not sure that they have not actually left their bodies. (1979, p. 34 )

A psychologist who had had experiences with LSD described ketamine as "experiments in voluntary death" (Leary, 1983, p. 375). Ramses Sputz noted:

One infrequent $K$ [ketamine] user reports a classic near-death experience during his first trip. "I was convinced I was dead. I was floating above my body. I reviewed all of the events of my life and saw a lot of areas where I could have done better." $(1989$, p. 65)

Psychiatrist Stanislav Grof stated: "If you have a full-blown experience of ketamine, you can never believe there is death or that death can possibly influence who you are" (Stevens, 1989, p. 481-482). Anesthesiologist Barbara Collier reported that "ketamine allows some patients to reason that ... the strange, unexpected intensity and 
unfamiliar dimension of their experience means they must have died" (Collier, 1981, p. 552).

Attempts to explain NDEs as hallucinations are sometimes rejected by spiritualists because many persons insist upon the reality of their experiences (Osis and Haraldsson, 1977; Ring, 1980). However, 30 percent of normal subjects given ketamine were certain that they had not been dreaming or hallucinating, but that the events had really happened (Rumpf, Pedick, Teuteberg, Munchhoff, and Nolte, 1969; Siegel, 1978). The American Psychiatric Association defined a hallucination as "a sensory perception that has the compelling sense of reality of a true perception but that occurs without external stimulation . . . . Transient hallucinatory experiences may occur in people without mental disorder" (American Psychiatric Association, 1994, p. 767).

The apparently clear sensorium of some persons who have had NDEs has also been used to argue that the NDE is "real" and not a hallucination (Osis and Haraldsson, 1977; Ring, 1980). It is thus important to note that hallucinations in schizophrenia typically occur in clear consciousness and are perceived to be real (American Psychiatric Association, 1994). A personal conviction of the "reality" of an NDE does not invalidate scientific explanations. Some users of LSD have claimed that their minds were clearer than usual, and that the LSD world is real while the "normal" world is a veil of illusion (Grinspoon and Bakalar, 1979). Cardiac arrest survivors sometimes describe their resuscitation in detail (Sabom, 1982). Ketamine can permit sufficient sensory input to allow accounts of procedures during which the patient appeared wholly unconscious (Siegel, 1981).

One of the objections that has been raised against ketamine models of the NDE is that NDEs have been reported to be characterized by a sense of peace and well-being (Ring, 1980), while ketamine experiences are sometimes unpleasant, involving considerable anxiety. This objection arises largely from the manner in which data have been collected. For example, to investigate the NDE as Ring did requires that one have a pre-existing definition of what one is investigating. Such a definition will exclude many other mental phenomena that may be produced by the same neurochemical events as the NDE, just as ketamine produces a considerably wider range of phenomena than the NDE. It is reasonable to suppose that if all persons who had a cardiac arrest and were "unconscious" for a period were to be interviewed, many would not be able to report an altered state of any kind, just as many persons given ketamine can recall 
nothing of the experience. There would then be varying percentages in both the cardiac arrest and ketamine groups who would report a range of phenomena, of which the NDE would be only one. Certainly a percentage of persons who have had cardiac arrests, for example, would report nightmares, anxiety, and panic.

Thus the argument that the neurochemical events induced by ketamine cannot explain "real" NDEs because ketamine also has other effects is weakened by the probability that factors precipitating "real" NDEs also have other psychological effects. As Rogo (1984) has pointed out, set and setting may go some way toward explaining the occasional incidence of anxiety reported in the ketamine literature. Anesthetists have reported that manipulations of set and setting can eliminate negative ketamine reactions (Cunningham and McKinney, 1983; Sklar, Zukin, and Reilly, 1981). It is also the case that ketamine's popular reputation for inducing nightmares is not well supported by the published scientific data; the "negative affect" is partly a myth. For example, the plastic surgeons Bruce Cunningham and Peter McKinney found "that many patients felt the hallucinatory phenomena to be pleasant and experienced no real concern or fear" (1983, p. 24). Garry Sklar, Stephen Zukin, and Thomas Reilly (1981) demonstrated that an informed patient who had good rapport with the anesthesiologist could experience the vivid imagery of full-dose ketamine without becoming frightened or alarmed. The marked increase in recreational use of ketamine (Stafford, 1992) is unlikely to have occurred were it to induce a large number of experiences characterized by negative affect.

Peter Stafford (1992) has described six broad categories of ketamine experience, and five of these can be related to near-death phenomena. This does not suggest that there is an endless heterogeneity of experience. A survey of both NDE and ketamine literatures does not support the argument that NDEs are more homogeneous and invariant than ketamine experiences.

\section{Glutamate, NMDA and Sigma Receptors, and the Hippocampus}

Most large neurons in the cerebral cortex use glutamate as their neurotransmitter. Glutamate, an excitatory amino acid, is central to the function of the hippocampus, a structure in the medial temporal lobe involved in memory and emotion and in integrating inputs from 
many parts of the brain (Cotman, Monaghan, Ottersen, and StormMathisen, 1987; Fagg and Foster, 1983; Greenamyre, Young, and Penney, 1984; Jansen, Faull, and Dragunow, 1989; Jansen, Faull, Dragunow, and Synek, 1990; Monaghan, Bridges, and Cotman, 1989; White, Nadler, Hamburger, Cotman, and Cummins, 1977) and plays a vital role in all cognitive processes involving the cerebral cortex, including thinking, memory, and perception (Monaghan, Bridges, and Cotman, 1989; Oye, Paulsen, and Maurset, 1992; Squire and ZolaMorgan, 1988).

There is a binding site for ketamine and PCP, called the PCP receptor, attached to the NMDA receptor (Monaghan, Bridges, and Cotman, 1989). As they are part of the same entity, the two terms "PCP receptor" and "NMDA receptor" are sometimes used interchangeably. It was formerly believed that the sigma and PCP sites were the same entity, but it is now clear that sigma receptors have a unique distribution in the central nervous system and are not a form of opioid receptor (Jansen, Faull, Dragunow, and Leslie, 1991; Walker, Bowen, Walker, Matsumoto, De Costa, and Rice, 1990).

When the glutamate theory of the NDE was first proposed (Jansen, $1990 \mathrm{~b}$ ), it was not clear whether the hallucinogenic properties of ketamine were due to NMDA or sigma receptors. It is now known that these effects are due to NMDA receptor blockade (Krystal, Karper, Seibyl, Freeman, Delaney, Bremner, Heninger, Bowers, and Charney, 1994), and that sigma receptors do not play an important role. Substances that bind to sigma receptors frequently have some affinity for NMDA and kappa opioid receptors at higher doses; but substances that bind to sigma receptors with a high degree of specificity, such as (+)pentazocine, do not produce NDEs at doses at which most of the binding is to sigma rather than NMDA and kappa opioid receptors (Musacchio, Klein, and Canoll, 1990; Walker, Bowen, Walker, Matsumoto, DeCosta, and Rice, 1990).

Glutamate is excitatory. When present in excess, neurons die via a process called excitotoxicity. This is the mechanism of neuronal cell death in hypoxia/ischemia and epilepsy, conditions that have been proven to lead to excessive release of glutamate (Rothman, 1984; Rothman and Olney, 1986, 1987). Blockade of PCP receptors prevents cell death from excitotoxicity (Meldrum, 1987; Rothman, Thurston, Hauhart, Clark, and Solomon, 1987). This suggests that the brain may have a protective mechanism against the detected glutamate flood: a counter-flood of a substance that binds to the PCP receptor, preventing cell death. The brain is a well-protected organ with many 
known defenses; it is reasonable to propose that it has protective mechanisms against excitotoxicity. This hypothetical defensive flood of substances to block the PCP receptors is the only speculation in the process outlined above; the other statements are strongly supported by experimental evidence (Ben-Ari, 1985; Benveniste, Drejer, Schousboe, and Diemer, 1984; Hoyer and Nitsch, 1989; King and Dingledine, 1986; Lobner and Lipton, 1990; Rothman, Thurston, Hauhart, Clark, and Solomon, 1987; Simon, Swan, Griffiths, and Meldrum, 1984; Westerberg, Monaghan, Cotman, and Wieloch, 1987). Endogenous substances have been found in the brain that bind to the PCP receptor, one of which is a peptide called alpha-endopsychosin (Quirion, DiMaggio, French, Contreras, Shiloach, Pert, Everist, Pert, and O'Donohue, 1984).

\section{Explanations for the NDE}

Some investigators have argued that the NDE must have a single explanation and then presented anecdotes to counter each of the scientific theories that have been proposed (for example, Ring, 1980) or have required that any scientific theory put forward must explain all of the experiences that have been labeled as NDEs (for example, Gabbard and Twemlow, 1989). It is more likely that the NDE is a final common expression of several different causes. Even then, the final "common" expression contains sufficient variability to suggest different types of NDE with different explanations. A multi-leveled interpretation is thus the most useful. The glutamate hypothesis of the NDE is not intended to apply to all NDEs, nor is it incompatible with many of the theories described below.

\section{Psychological hypotheses}

Depersonalization. The NDE may be an adaptive mechanism that alerts one to the threat of death while potentially overwhelming emotion is held at bay, allowing the reality to be integrated without panic (Greyson, 1983; Noyes and Kletti, 1976a, 1976b). This model is applicable when death is psychologically near, as in falling from a cliff. While protecting nerve cells from ischemic damage is then largely irrelevant, glutamate and NMDA receptors would certainly be in- 
volved in producing the experience, as they play a key role in cognition and perception.

Regression in the Service of the Ego. Confronting death cuts off the external world, resulting in regression to a preverbal level of development experienced as mystical ineffability (Greyson, 1983). Loss of contact with the external world is one of the most characteristic effects of ketamine, and is probably due to blockade of NMDA receptors involved in sensory transmission. NMDA receptors play a central role in the transmission of incoming signals from all sensory modalities (Cline, Debski, and Constantine-Paton, 1987; Cotman, Monaghan, Ottersen, and Storm-Mathisen, 1987; Davies and Watkins, 1983; Greenamyre, Young, and Penney, 1984; Headley, West, and Roe, 1985; Kisvardy, Cowey, Smith, and Somogyi, 1989; Monaghan, Bridges, and Cotman, 1989; Oye, Paulsen, and Maurset, 1992).

State-Dependent Reactivation of Birth Memories. Movement through tunnels towards light may be a memory of being born, a "near-birth experience" (Grof and Halifax, 1977). NMDA receptor blockade could be the underlying mechanism for such a reactivation of primitive memories.

Sensory Deprivation. John Lilly (1978) explored ketamine as a means of inducing sensory deprivation, as a development of his work with sensory deprivation induced by flotation tanks. The observation that ketamine induces sensory deprivation was also explored by Barbara Collier (1972), who provided detailed accounts of NDEs induced by ketamine, including patients who claimed that they had died, separated from their bodies, and ascended to heaven.

How can sensory deprivation produce an altered state of consciousness? Memories may normally be suppressed by a mechanism that acts as a gate, admitting primarily external signals when we are fully conscious and concentrating on an external task (Siegel, 1980, 1981). If this input is dramatically reduced, for example, by ketamine or a heart attack, in combination with central stimulation, for example, by excessive glutamate release during hypoxia or epilepsy, stored perceptions are released and become "organized" into a meaningful experience by the mind (Greyson, 1983).

The hippocampus is the anatomical location of such a gate, and NMDA receptors form the molecular substrate of the gate. NMDA receptors have their highest concentration in the hippocampus, a part of the medial temporal lobe where data from the external world are integrated with internal programs. The NMDA receptor plays an important role in learning, and in the formation and retrieval of memo- 
ries. The PCP receptor is referred to as a "gated channel" (Foster and Flagg, 1987). Whether the gate is open or closed depends on the degree of excitation, specifically, the position of a magnesium ion in the channel (Mayer, Westbrook, and Guthrie, 1984). Ketamine blocks this channel and closes the gate to incoming data (Collingridge, 1987; Cotman, Monaghan, and Ganong, 1988; McNaughton and Morris, 1987; Monaghan, Bridges, and Cotman, 1989; Morris, Anderson, Lynch, and Baudry, 1986).

The "white light" may result from central nervous system stimulation mimicking light on the retina, and a lowering of the phosphene perceptual threshold (Siegel, 1980, 1981). Sensory deprivation itself can produce profound alterations in consciousness (Lilly, 1961, 1978).

\section{Drug-Induced Hallucinations}

Administered drugs may explain some cases of NDEs, but in many no drugs were given with effects resembling the NDE (Sabom, 1982).

\section{Temporal Lobe Epilepsy}

Michael Persinger and Kate Makarec (1987) and Juan SaavedraAguilar and Juan Gómez-Jeria (1989) have reviewed evidence for the similarity between the phenomena experienced in temporal lobe epilepsy and NDEs. Glutamate is the key neurotransmitter in the temporal lobe, particularly in the hippocampus, and plays an important role in epilepsy. The neuropathology of epilepsy is believed to result from excitotoxic cell death (Ben-Ari, 1985; Cotman, Monaghan, and Ganong, 1988; King and Dingledine, 1986; Mody and Heinemann, 1987; Olney, Collins, and Sloviter, 1986; Sloviter, 1983).

It is possible that the postulated endogenous neuroprotective system becomes active in any excitotoxic situation, including temporal lobe epilepsy. The degree of excitotoxic cell damage, and the mental state, resulting from an incident in which there is a glutamate flood, whatever the cause, may depend on the final balance in each neuronal pathway between excitotoxic forces and neuroprotective mechanisms. This theory is supported by reports of persons who were oxygen deprived for prolonged periods, had a profound NDE, and survived the episode unimpaired (Sabom, 1982). The lack of apparent brain damage in these cases is hard to explain unless we postulate 
that these may be persons with a particularly effective mechanism for glutamatergic blockade.

It is also possible that there is no protective mechanism, and that ketamine exerts its effects by mimicking some of the processes seen in temporal lobe epilepsy. Even though ketamine blocks glutamatergic transmission and prevents excitotoxic cell death, the effect of ketamine upon the human electroencephalograph (EEG) suggests that the final result of ketamine acting in the brain is the result of a complex interplay of forces. There is a reduction in alpha wave activity, while beta, delta, and theta wave activity are increased (Pichlmayr, Lips, and Kunkel, 1984; Schwartz, Virden, and Scott, 1974).

Ketamine has been reported to act both as an anticonvulsant (Celesia and Chen, 1974; Leccese, Marquis, Mattia, and Moreton, 1986; Mares, Lansitiakova, Vankova, Kubova, and Velisek, 1992; McCarthy, Chen, Kaump, and Ensor, 1965; Taberner, 1976) and as a convulsant (Bennet, Madsen, Jordan, and Wiser, 1973; Gourie, Cherian, and Shankar, 1983; Myslobodsky, Golovchinsky, and Mintz, 1981). M. S. Myslobodsky, V. Golovchinsky, and M. Mintz (1981) reported that ketamine could produce epileptiform EEG patterns in human limbic and thalamic regions, but that there was no evidence that this affected other cortical regions or that clinical seizures were likely to occur. This is quite consistent with the NDE model presented by Saavedra-Aguilar and Gómez-Jeria (1989) involving limited electrical abnormalities in the limbic system.

Thus the production of NDEs by ketamine is not necessarily at odds with the proposal that NDEs may result from abnormal electrical activity. David Reich and George Silvay concluded: "It is hard to draw objective conclusions regarding the anti-convulsant properties of ketamine . . . Animal data are particularly difficult to interpret, because of inter-species variations" (1989, p. 188). Nevertheless, the weight of the evidence favors the conclusion that ketamine is probably anticonvulsant at the doses required to produce the NDE (Myslobodsky, Golovchinsky, and Mintz, 1981), favoring the hypothesis that an NMDA receptor blocker is released to produce the NDE.

Franz Vollenweider (1996) recently investigated the effects of ketamine using fluorodeoxyglucose-positron emission tomography (FDG-PET), a method that permits the imaging of metabolic activity in the brain. Subjects were given the drug and then had their altered states assessed using the Altered States of Consciousness Question- 
naire, the Ego Pathology Inventory, and the inventory of the Association for Methodology and Documentation in Psychiatry. Imaging of brain activity indicated that "oceanic boundlessness" was strongly correlated with metabolic hyperactivity in the frontal cortex, "visionary restructuralization" was linked mainly to changes in the occipital cortex, and "dread of ego dissolution" was linked with changes in the thalamus and subcortical areas.

\section{Endorphin Release}

Daniel Carr $(1981,1989)$ proposed that NDEs resulted from a flood of endogenous opioids, or endorphins, as survival time was increased by giving opiate antagonists, such as naloxone, in fatal circumstances (Holaday and Faden, 1978). More recently, a sudden increment of beta-endorphin has been reported in the brain and body fluids of dogs who are "conscious" at the moment of death (Sotelo, Perez, Guevara, and Fernandez, 1995). The concept of a flood release of endogenous compounds is valuable, and it has now been established, as noted above, that a glutamate flood results in excitotoxic cell death in hypoxia/ischemia and epilepsy.

However, endorphins are not responsible for the NDE, as they are not potent hallucinogens (Oyama, Jin, Yamaga, Ling, and Guillemin, 1980). Injection of beta-endorphin into the cerebrospinal fluid has analgesic effects lasting well over 22 hours (Oyama, Jin, Yamaga, Ling, and Guillemin, 1980). This does not match the time course of a typical NDE, which is relatively brief.

Ketamine produces brief, deep analgesia (White, Way, and Trevor, 1982) due to NMDA or PCP receptor blockade (Parsons, Gibbens, Magnago, and Headley, 1988; Schoenberg and Sjolund, 1986). The limited psychotomimetic properties of some opioids, such as (-)pentazocine, result from binding to kappa opioid receptors, and to PCP receptors at higher doses (Musacchio, Klein, and Canoll, 1990; Pfieffer, Brantl, Jerz, and Emrich, 1986). However, the effects of (-)pentazocine binding to kappa receptors are described as feelings of cheerfulness and strength (Bellville and Forrest, 1968). The effects of selective and specific drug binding to kappa receptors do not match the profound alterations in consciousness produced by ketamine. With higher doses, more marked effects may appear as a result of binding to PCP receptors. 
Claims that sigma-selective (+)isomers of benzomorphan opiates have psychotomimetic effects are not supported by the extensive literature based on research in humans, carried out in the 1960s, which demonstrated that it is the (-)isomers that have psychotomimetic properties, and those may prefer PCP receptors rather than sigma sites (Musacchio, Klein, and Canoll, 1990). The naloxone-reversible component is due to kappa opioid receptor binding, while the naloxone-insensitive component is due to PCP or NMDA receptor binding, not sigma binding (Walker, Bowen, Walker, Matsumoto, De Costa, and Rice, 1990). The role of opioid receptors in ketamine effects is controversial (Reich and Silvay, 1989). Naloxone could not reverse the effects of ketamine in humans (Amiot, Bouju, and Palacci, 1985), nor in dogs (Vaupel, 1983).

It is important to note that ketamine is supplied as a mixture of $(+)$ ketamine and (-)ketamine isomers. Some of the controversy may be resolved by an improved understanding of the separate effects of the isomers and the doses at which they appear. As doses rise, the probability that drugs will bind to a wider range of receptors also rises. In this context, it is important to note that ketamine can induce NDEs at doses about four times less than those required for anesthesia (Grinspoon and Bakalar, 1979; Lilly, 1978; Sputz, 1989; Stafford, 1977).

Paul White, Jay Ham, Walter Way, and Anthony Trevor (1980) reported that it was (+)ketamine that has some opioid binding properties and that produced the most anesthesia, while (-)ketamine produced more "psychic emergence reactions," or NDEs. White, Jurgen Schuttler, Audrey Schafer, Donald Stanski, Yukio Horai, and Trevor (1985) went on to show that (+)ketamine is about four times more potent as a hypnotic and analgesic, and has different effects upon the EEG than (-)ketamine, which may explain some of the confusion concerning whether ketamine is an anticonvulsant or a convulsant (Myslobodsky, Golovchinsky, and Mintz, 1981).

Saavedra-Aguilar and Gómez-Jeria (1989) have presented evidence from animal experiments that beta-endorphin may be epileptogenic (Henriksen, Bloom, McCoy, Ling, and Guillemin, 1978; McGinty, Kanamatsu, Obie, and Hong, 1986) to support their argument that beta-endorphin produces NDEs. While beta-endorphin may have these effects within the rat experimental paradigms used, it is common clinical experience that opioids do not induce epilepsy in humans (Meltzer, 1987). It seems more probable that released peptides would have protective functions rather than contributing further to excito- 
toxicity. Saavedra-Aguilar and Gómez-Jeria (1989) also cited the finding of Tsung-Ping Su, Edythe London, and Jerome Jaffe (1988) that some steroids bind to sigma receptors, suggesting that steroids could play a role in NDEs. In fact, the steroid in question was progesterone, which is certainly not a hallucinogen, and S. Schwarz, P. Pohl, and G.-Z. Zhou (1989) have suggested that the affinity of progesterone for the sigma site is insufficient to result in significant receptor occupancy. It is possible that the endogenous ligand for the PCP channel is not a peptide but an ion or some other class of compound. Magnesium and zinc are involved in inhibiting the action of the NMDA receptor (Cotman, Monaghan, and Ganong, 1988; Thomson, 1986; Westbrook and Mayer, 1987).

\section{Abnormalities in Blood Gases}

Hypoxia. Richard Blacher (1980) suggested that hypoxia might give rise to the NDE. This proposal has been criticized by some authors (Sabom, 1982), because studies involving a slow fall in inspired oxygen produce mental clouding rather than NDEs (Henderson and Haggard, 1927). However, these studies are not an accurate model of events in, for example, cardiac arrest. Sudden hypoxia causes an excessive release of glutamate with resulting excitotoxicity, which can be prevented, as noted above, by ketamine.

Hypercapnia. A carbon-dioxide-enriched breathing mixture can result in typical near-death phenomena such as bodily detachment and the perception of being drawn towards a bright light. Diverse personality types produced similar reports, suggesting a shared neurological substrate (Meduna, 1950).

\section{Serotonin}

Like endorphins, serotonin effects may be contributory but do not play a central role in the NDE. Psychedelic drugs such as LSD are serotonergic in action, yet the psychedelic mental state is very different from the NDE. LSD frequently involves an overwhelming increase in sensory input from the external environment (Grinspoon and Bakalar, 1979), in sharp contrast to the cataleptic dissociation produced by ketamine. Psychedelic visual phenomena bear little relationship to the dreamlike images of ketamine and the NDE. The 
"ego dissolution" experienced on LSD has a different quality from the conviction of having died that may arise with ketamine, and loss of contact with the external environment leading rapidly to the "tunnel experience" is not a typical psychedelic drug effect, although it may occur. Alexander Shulgin, a pioneer in the psychedelic movement, has argued that the dissociative anesthetics have little in common with psychedelic drugs (Shulgin and Shulgin, 1991).

\section{Conclusion}

The NDE is an important phenomenon that can safely be reproduced by ketamine, and the glutamate theory of the NDE can thus be investigated by experiment. Recent advances in neuroscience strongly suggest a common origin for ketamine experiences and the NDE in events occurring at glutamatergic synapses, mediated by the NMDA (PCP) receptor.

This theory represents an extension of previous hypotheses, and incorporates most of the neurobiological and psychological theories that have been put forward. It links many of these ideas, such as hypoxia, peptide release, temporal lobe epilepsy, regression in the service of the ego, reactivation of birth memories, and sensory deprivation, rather than being an alternative to them. Most of the planks on which this hypothesis is built are strongly supported by experimental evidence implicating glutamate and the NMDA receptor as unifying entities in the processes leading to an NDE. The main exception to this is the postulate that anti-excitotoxic agents can flood the brain, which remains to be clearly established.

\section{References}

American Psychiatric Association (1994). Diagnostic and statistical manual of mental disorders (4th ed.). Washington, DC: American Psychiatric Association.

Amiot, J. F., Bouju, P. and Palacci, J. H. (1985). Effect of naloxone on loss of consciousness induced by i.v. ketamine [Letter]. British Journal of Anaesthesia, 57, 930.

Anis, N. A, Berry, S. C., Burton, N. R. and Lodge, D. (1983). The dissociative anaesthetics, ketamine and phencyclidine, selectively reduce excitation of central mammalian neurones by N-methyl-aspartate. British Journal of Pharmacology, 79, 565-575.

Barnes, D. M. (1988). NMDA receptors trigger excitement. Science, 239, 254-256.

Ben-Ari, Y. E. (1985). Limbic seizure and brain damage produced by kainic acid: Mechanisms and relevance to human temporal lobe epilepsy. Neuroscience, 14, 375-403.

Bellville, J. W., and Forrest, W. (1968). Respiratory and subjective effects of d- and l-pentazocine. Clinical Pharmacology and Therapeutics, 9, 142-151. 
Bennett, D. R., Madsen, J. A., Jordan, W. S., and Wiser, W. C. (1973). Ketamine anesthesia in brain-damaged epileptics: Electroencephalographic and clinical observations. Neurology, 23, 449-450.

Benveniste, H., Drejer, J., Schousboe, A. and Diemer, N. H. (1984). Elevation of the extracellular concentrations of glutamate and aspartate in rat hippocampus during cerebral ischemia monitored by microdialysis. Journal of Neurochemistry, 43, 1369 1374.

Blacher, R. S. (1980). The near-death experience [Letter]. Journal of the American Medical Association, 244, 30.

Carr, D. B. (1981). Endorphins at the approach of death [Letter]. Lancet, 1, 390.

Carr, D. B. (1989). On the evolving neurobiology of the near-death experience: Comments on "A neurobiological model for near-death experiences." Journal of NearDeath Studies, 7, 251-254.

Celesia, G. G. and Chen, R. (1974). Effects of ketamine on EEG activity in cats and monkeys. Electroencephalography and Clinical Neurophysiology, 37, 345-353.

Choi, D. W. (1988). Glutamate neurotoxicity and diseases of the nervous system. Neuron, 1, 623-634.

Cline, H. T., Debski, E. A., and Constantine-Paton, M. (1987). N-methyl-D-aspartate receptor antagonist desegregates eye-specific stripes. Proceedings of the National Academy of Sciences, 84, 4342-4345.

Coan, E. J., and Collingridge, G. L. (1987). Effects of phencyclidine, SKF 10,047 and related psychotomimetic agents on $\mathrm{N}$-methyl- $\mathrm{D}$-aspartate receptor mediated synaptic responses in rat hippocampal slices. British Journal of Pharmacology, 91, 547-556.

Collier, B. B. (1972). Ketamine and the conscious mind. Anaesthesia, 27, 120-134.

Collingridge, G. L. (1987). The role of NMDA receptors in learning and memory. Nature, 330, 604-605.

Contreras, P. C., DiMaggio, D. A., and O'Donohue, T. L. (1987). An endogenous ligand for the sigma opioid binding site. Synapse, 1, 57-61.

Cotman, C. W., and Monaghan, D. T. (1987). Chemistry and anatomy of excitatory amino acid systems. In H. Y. Meltzer (Ed.), Psychopharmacology: The third generation of progress (pp. 197-218). New York, NY: Raven Press.

Cotman, C. W., Monaghan, D. T., Ottersen, O. P., and Storm-Mathisen, J. (1987). Anatomical organization of excitatory amino acid receptors and their pathways. Trends in Neurosciences, 107, 273-279.

Cotman, C. W., Monaghan, D. T., and Ganong, A. H. (1988). Excitatory amino acid neurotransmission: NMDA receptors and Hebb-type synaptic plasticity. Annual Review of Neuroscience, 11, 61-80.

Cunningham, B. L., and McKinney, P. (1983). Patient acceptance of dissociative anesthetics. Plastic and Reconstructive Surgery, 72, 22-26.

Davies, J., and Watkins, J. C. (1983). Role of excitatory amino acid receptors in monoand polysynaptic excitation in the cat spinal cord. Experimental Brain Research, 49, 280-290.

Domino, E. F., Chodoff, P., and Corssen, G. (1965). Pharmacologic effects of CI-581, a new dissociative anesthetic, in man. Clinical Pharmacology and Therapeutics, 6, 279-291.

Fagg, G. E., and Foster, A. C. (1983). Amino acid neurotransmitters and their pathways in the mammalian central nervous system. Neuroscience, 9, 701-771.

Foster, A, and Fagg, G. E. (1987). Taking apart NMDA receptors. Nature, 329, 395.

Gabbard, G. O., and Twemlow, S. T. (1989). Comments on "A neurobiological model for near-death experiences." Journal of Near-Death Studies, 7, 261-264.

Ghoneim, M. M., Hinrichs, J. V., Mewaldt, S. P., and Peterson, R. C. (1985). Ketamine: Behavioral effects of subanesthetic doses. Journal of Clinical Psychopharmacology, 5, 70-77. 
Gourie, D. M., Cherian, L., and Shankar, S. K (1983). Seizures in cats induced by ketamine hydrochloride anaesthesia. Indian Journal of Medical Research, 77, 525528.

Greenamyre, J. T., Young, A. B., and Penney, J. B. (1984). Quantitative autoradiographic distribution of $1-\left[{ }^{3} \mathrm{H}\right]$ glutamate binding sites in rat central nervous system. Journal of Neuroscience, 4, 2133-2144.

Greyson, B. (1983). The psychodynamics of near-death experiences. Journal of Nervous and Mental Disease, 171, 376-380.

Greyson, B., and Stevenson, I. (1980). The phenomenology of near-death experiences. American Journal of Psychiatry, 137, 1193-1196.

Grinspoon, L., and Bakalar, J. B. (1979). Psychedelic drugs reconsidered. New York, NY: Basic Books.

Grof, S., and Halifax, J. (1977). The human encounter with death. New York, NY: Dutton.

Headley, P. M., West, D. C., and Roe, C. (1985). Actions of ketamine and the role of $\mathrm{N}$-methyl-aspartate receptors in the spinal cord: Studies on nociceptive and other neuronal responses. Neurological Neurobiology, 14, 325-335.

Henderson, Y., and Haggard, H. W. (1927). Noxious gases and the principles of respiration influencing their action. New York, NY: American Chemical Society.

Henriksen, S. J., Bloom, F. E., McCoy, F., Ling, N., and Guillemin, R. (1978). B-endorphin induces nonconvulsive limbic seizures. Proceedings of the National Academy of Science, 75, 5221-5225.

Holaday, J. W., and Faden, A. L. (1978). Naloxone reversal of endotoxin hypotension suggests role of endorphins in shock. Nature, 275, 450-451.

Hoyer, S., and Nitsch, R. (1989). Cerebral excess release of neurotransmitter amino acids subsequent to reduced cerebral glucose metabolism in early-onset dementia of Alzheimer type. Journal of Neural Transmission, 75, 226-232.

Jansen, K. L. R. (1989a). The near-death experience [Letter]. British Journal of Psychiatry, 154, 882-883.

Jansen, K L. R. (1989b). Near-death experience and the NMDA receptor [Letter]. British Medical Journal, 298, 1708.

Jansen, K. L. R. (1990a). Ketamine: Can chronic use impair memory? International Journal of Addictions, 25, 133-139.

Jansen, K. L. R. (1990b). Neuroscience and the near-death experience: Roles for the NMDA-PCP receptor, the sigma receptor and the endopsychosins. Medical Hypotheses, 31, 25-29.

Jansen, K. L. R. (1991). Transcendental explanations and the near-death experience [Letter]. Lancet, 337, 244.

Jansen, K. L. R. (1993). Non-medical uses of ketamine. British Medical Journal, 298, 4708-4709.

Jansen, K. L. R., and Faull, R. L. M. (1991). Excitatory amino acids, NMDA and sigma receptors: A role in schizophrenia? Behavioural and Brain Sciences, 14, 34-35.

Jansen, K. L. R., Faull, R. L. M., and Dragunow, M. (1989). Excitatory amino acid receptors in the human cerebral cortex: A quantitative autoradiographic study comparing the distribution of $\left[{ }^{3} \mathrm{H}\right] \mathrm{TCP},\left[{ }^{3} \mathrm{H}\right]$ glycine, $1-\left[{ }^{3} \mathrm{H}\right]$ glutamate, $\left[{ }^{3} \mathrm{H}\right] \mathrm{AMPA}$ and $\left[{ }^{3} \mathrm{H}\right]$ kainic acid binding sites. Neuroscience, 32, 587-607.

Jansen, K. L. R., Faull, R. L. M., Dragunow, M., and Leslie, R. (1991). Autoradiographic distribution of sigma receptors in human neocortex, hippocampus, basal ganglia, cerebellum, pineal and pituitary glands. Brain Research, 559, 172-177.

Jansen, K. L. R., Faull, R. L. M., Dragunow, M. and Synek, B. (1990). Alzheimer's disease: Changes in hippocampal N-methyl-D-aspartate, quisqualate, neurotensin, adenosine, benzodiazepine, serotonin and opioid receptors-An autoradiographic study. Neuroscience, $39,613-617$. 
King, G. L., and Dingledine, R. (1986). Evidence for the activation of the N-methylD-aspartate receptor during epileptic discharge. In R. Schwartz and Y. Ben-Ari (Eds.), Excitatory amino acids and epilepsy (pp. 520-570). New York, NY: Plenum.

Kisvardy, Z. F., Cowey, A., Smith, A. D., and Somogyi, P. (1989). Interlaminar and lateral excitatory amino acid connections in the striate cortex of monkey. Journal of Neuroscience, 9, 667-682.

Krystal, J. H., Karper, L. P., Seibyl, J. P., Freeman, G. K, Delaney, R., Bremner, J. D., Heninger, G. R., Bowers, M. B., and Charney, D. S. (1994) Subanesthetic effects of the noncompetitive NMDA antagonist, ketamine, in humans. Archives of General Psychiatry, 51, 199-214.

Leary, T. F. (1983). Flashbacks: An autobiography. Los Angeles, CA: Tarcher.

Leccese, A. P., Marquis, K. L., Mattia, A., and Moreton, J. E. (1986). The anticonvulsant and behavioural effects of phencyclidine and ketamine following chronic treatment in rats. Behavioral Brain Research, 22, 257-233.

Lilly, J. C. (1961). Experiments in solitude, in maximum achievable physical isolation with water suspension, of intact healthy persons. In B. Flaherty (Ed.), Physiological aspects of space flight (pp. 238-247). New York, NY: Columbia University Press.

Lilly, J. C. (1978). The scientist: $A$ novel autobiography. New York, NY: Bantam/Lippincott.

Lobner, D., and Lipton, P. (1990). $\sigma$-ligands and non-competitive NMDA antagonists inhibit glutamate release during cerebral ischemia. Neuroscience Letters, 117, 169174.

Mares, P., Lansitiakova, M., Vankova, S., Kubova, H., and Velisek, L. (1992). Ketamine blocks cortical epileptic afterdischarges but not paired-pulse and frequency potentiation. Neuroscience, 50, 339-344.

Mayer, M. L., Westbrook, G. L., and Guthrie, P. B. (1984), Voltage-dependent block by $\mathrm{Mg}^{2+}$ of NMDA receptors in spinal cord neurons. Nature, 309, 261-263.

McCarthy, D. A. (1981). History of the development of cataleptoid anesthetics of the phencyclidine type. In E. F. Domino (Ed.), Phencyclidine: Historical and current perspectives (pp. 80-115). Ann Arbor, MI: NPP Books.

McCarthy, D. A., Chen, G., Kaump, D. H., and Ensor, C. J. (1965). General anesthetic and other pharmacological properties of 2-(O-chlorophenyl)-2-methylamino cyclohexanone $\mathrm{HCl}$ (CI-581). Journal of New Drugs, 5, 21-33.

McGinty, J. F., Kanamatsu, T., Obie, J., and Hong, J. S. (1986). Modulation of opioid peptide metabolism by seizures: Differentiation of opioid subclasses. National Institute of Drug Abuse Research Monographs, 71, 89-101.

McNaughton, B. C., and Morris, R. G. M. (1987). Hippocampal synaptic enhancement and information storage within a distributed system. Trends in Neurosciences, 10, 408-415.

Meduna, L. J. (1950). The effect of carbon dioxide upon the functions of the brain. In L. J. Meduna (Ed.), Carbon dioxide therapy (pp. 23-40). Springfield, IL: Charles C Thomas.

Meldrum, B. S., Evans, M. C., Swan, J. H., and Simon, R. P. (1987). Protection against hypoxic/ischaemic brain damage with excitatory amino acid antagonists. Medical Biology, 65, 153-157.

Meltzer, H. Y. (Ed.). (1987). Psychopharmacology; The third generation of progress. New York, NY: Raven Press.

Mody, I., and Heinemann, U. (1987). NMDA receptors of dentate gyrus cells participate in synaptic transmission following kindling. Nature, 326, 701-703.

Monaghan, D. T., Bridges, R. J., and Cotman, C. W. (1989). The excitatory amino acid receptors: Their classes, pharmacology and distinct properties in the function of the nervous system. Annual Review of Pharmacology and Toxicology, 29, 365-402.

Moody, R. A. (1975). Life after life. Covington, GA: Mockingbird Books. 
Morris, R. G. M., Anderson, E., Lynch, G. S., and Baudry, M. (1986). Selective impairment of learning and blockade of EPT by NMDA antagonist AP5. Nature, 319, 744-776.

Morse, M. L. (1989). Comments on "A neurobiological model for near-death experiences." Journal of Near-Death Studies, 7, 223-228.

Morse, M. L., Conner, D., and Tyler, D. (1985). Near-death experiences in a pediatric population. American Journal of Diseases of Children, 139, 595-563.

Musacchio, J. M., Klein, M., and Canoll, P. D. (1990). Dextromethorphan sites, sigma receptors and the psychotomimetic effects of sigma opiates. Progress in Clinical and Biological Research, 328, 13-16.

Myslobodsky, M. S., Golovchinsky, V., and Mintz, M. (1981). Ketamine: Convulsant or anticonvulsant? Pharmacology, Biochemistry, and Behavior, 14, 27-33.

Nowak, L., Bergestovski, P., Ascher, P., Herbet, A., and Prochiantz, A. (1984). Magnesium gates glutamate-activated channels in mouse central neurons. Nature, 307, $462-465$.

Noyes, R., and Kletti, R. (1976a). Depersonalization in the face of life threatening danger: A description. Psychiatry, 39, 19-30.

Noyes, R., and Kletti, R. (1976b). Depersonalization in the face of life threatening danger: An interpretation. Omega, 7, 103-108.

Olney, J. W., Collins, R. C., and Sloviter, R. S. (1986). Excitotoxic mechanisms of epileptic brain damage. Advances in Neurology, 44, 857-877.

Osis, K and Haraldsson, E. (1977). At the hour of death. New York, NY: Avon.

Oyama, T.Y., Jin, T., Yamaga, R., Ling, N. and Guillemin, R. (1980). Profound analgesic effects of $B$-endorphin in man. Lancet, 1, 122-124.

Oye, N., Paulsen, O., and Maurset, A. (1992). Effects of ketamine on sensory perception: Evidence for a role of N-methyl-D-aspartate receptors. Journal of Pharmacology and Experimental Therapeutics, 260, 1209-1213.

Parsons, C. G., Gibbens, H., Magnago, T. S. I., and Headley, P. M. (1988). At which 'sigma' site are the spinal actions of ketamine mediated? Neuroscience Letters, 85, 322-328.

Persinger, M. A., and Makarec, K. (1987). Temporal lobe epileptic signs and correlative behaviors displayed by normal populations. Journal of General Psychology, 114, 179195.

Pichlmayr, I., Lips, U., and Kunkel, H. (1984). The electroencephalogram in anaesthesia. Berlin, Germany: Springer-Verlag.

Peters, S., Koh, J., and Choi, D. W. (1987). Zinc selectively blocks the action of Nmethyl-D-aspartate on cortical neurons. Science, 236, 589-592.

Pfieffer, A., Brantl, V., Herz, A., and Emrich, H. M. (1986). Psychotomimesis mediated by opiate receptors. Science, 233, 774-776.

Quirion, R., Chicheportiche, R., Contreras, P. C., Johnston, K. M., Lodge, D., Tam, S. W., Woods, J.H., and Zukin, S. R. (1987). Classification and nomenclature of phencyclidine and sigma receptor sites. Trends in Neurosciences, 10, 444-446.

Quirion, R., DiMaggio, D. A., French, E. D., Contreras, P. C., Shiloach, J., Pert, C. B., Everist, H., Pert, A., and O'Donohue, T. L. (1984). Evidence for an endogenous peptide ligand for the phencyclidine receptor. Peptides, 5, 967-977.

Reich, D. L., and Silvay, G. S. (1989). Ketamine: An update on the first twenty-five years of clinical experience. Canadian Journal of Anaesthesia, 36, 186-197.

Ring, K. (1980). Life at death: A scientific investigation of the near-death experience. New York, NY: Coward, McCann, and Geoghegan.

Rogo, D. S. (1984). Ketamine and the near-death experience. Anabiosis: The Journal of Near-Death Studies, 4, 87-96.

Rothman, S. M. (1984). Synaptic release of excitatory amino acid neurotransmitter mediates anoxic neuronal death. Journal of Neuroscience, 4, 1884-1891. 
Rothman, S. M., and Olney, J. W. (1986). Glutamate and the pathophysiology of hypoxic-ischemic brain damage. Annals of Neurology, 19, 105-111.

Rothman, S. M., and Olney, J. W. (1987). Excitotoxicity and the NMDA receptor. Trends in Neurosciences, 107, 299-302.

Rothman, S. M., Thurston, J. H., Hauhart, R. E., Clark, G. P., and Solomon, J. S. (1987). Ketamine protects hippocampal neurons from anoxia in vitro. Neuroscience, 21, 673-683.

Rumpf, K., Pedick, J., Teuteberg, H., Munchhoff, W. and Nolte, H. (1969). Dream-like experiences during brief anaesthesia with ketamine, thiopental and propiadid. In H. Dreuscher (Ed.), Ketamine (pp. 161-180). Berlin, Germany: Springer-Verlag.

Saavedra-Aguilar, J. C., and Gómez-Jeria, J. S. (1989). A neurobiological model for near-death experiences. Journal of Near-Death Studies, 7, 205-222.

Sabom, M. B. (1982). Recollections of death: A medical investigation. New York, NY: Harper and Row.

Schoenberg, J., and Sjolund, B. H. (1986). First order nociceptive synapses in rat dorsal horn are blocked by an amino acid antagonist. Brain Research, 379, 394-398.

Schwartz, M. S., Virden, S., and Scott, D. F. (1974). Effects of ketamine on the electroencephalograph. Anaesthesia, 29, 135-140.

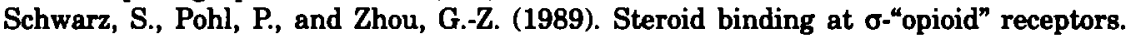
Science, 246, 1635-1637.

Shulgin, A., and Shulgin, A. (1991). Pihkal: A chemical love story. Berkeley, CA: Transform Press.

Siegel, R. K. (1978). Phencyclidine and ketamine intoxication: A study of recreational users. In R. C. Peterson and R. C. Stillman (Eds.), Phencyclidine abuse: An appraisal (National Institute of Drug Abuse Research Monograph Number 21) (pp. 119-140). Rockville, MD: National Institute of Drug Abuse.

Siegel, R. K. (1980). The psychology of life after death. American Psychologist, 35, 911-950.

Siegel, R. K. (1981, January). Accounting for "afterlife" experiences. Psychology Tbday, pp. 65-75.

Simon, R. P., Swan, S. H., Griffiths, T., and Meldrum, B. S. (1984). Blockade of Nmethyl-D-aspartate receptors may protect against ischemic damage in the brain. Science, 226, 850-852.

Sklar, G. S., Zukin, S. R., and Reilly, T. A. (1981). Adverse reactions to ketamine anaesthesia: Abolition by a psychological technique. Anaesthesia, 36, 183-187.

Sloviter, R. S. (1983). "Epileptic" brain damage in rats induced by sustained electrical stimulation of the perforant path. Brain Research Bulletin, 10, 675-697.

Sonders, M. S., Keana, J. F., Weber, E. (1988). Phencyclidine and psychotomimetic sigma opiates: Recent insights into their biochemical and physiological sites of action. Trends in Neurosciences, 11, 37-40.

Sotelo, J., Perez, R., Guevara, P., and Fernandez, A. (1995). Changes in brain, plasma and cerebrospinal fluid contents of B-endorphin in dogs at the moment of death. Neurological Research, 17, 223-225.

Sputz, R. (1989, October). I never met a reality I didn't like: A report on 'Vitamin

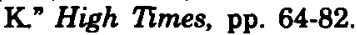

Squire, L. R., and Zola-Morgan, S. (1988). Memory: Brain systems and behavior. Trends in Neurosciences, 11, 170-175.

Stafford, P. (1977). Psychedelics encyclopedia. Berkeley, CA: And/Or Press.

Stafford, P. (1992). Psychedelics encyclopedia (third expanded ed.). Berkeley, CA: Ronin Publishing.

Stevens, J. (1988). Storming heaven: $L S D$ and the American dream. New York, NY: HarperCollins.

Stevenson, I., and Greyson, B. (1979). Near-death experiences: Relevance to the question of survival after death. Journal of the American Medical Association, 242, 265-267. 
Su, T. P., London, E. D., and Jaffe, J. H. (1988). Steroid binding at $\sigma$ receptors suggests a link between endocrine, nervous and immune systems. Science, 240, 219-223.

Taberner, P. V. (1976). The anticonvulsant activity of ketamine against seizures induced by pentylenetetrazol and mercaptopropionic acid. European Journal of Pharmacology, 39, 305-311.

Thomson, A. M. (1986). A magnesium-sensitive post-synaptic potential in rat cerebral cortex resembles neuronal responses to N-methylaspartate. Journal of Physiology, 370, 531-549.

Thomson, A. M., West, D. C., and Lodge, D. (1985). An N-methylaspartate receptormediated synapse in rat cerebral cortex: A site of action of ketamine? Nature, 313, 479-481.

Vaupel, D. B. (1983). Naltrexone fails to antagonize the effects of PCP and SKF 10,047 in the dog. European Journal of Pharmacology, 92, 269-274.

Vollenweider, F. X. (1996). Relationship of altered states of consciousness and principal components of brain energy metabolism by FDG-PET. In M. Schlichting (Ed.), Welten des Bewusstseins/Worlds of Consciousness: Abstracts of the 2nd International Congress of the European College for the Study of Consciousness, Band 6 Vol. (pp. 29-30). Berlin, Germany: Verlag für Wissenschaft und Bildung.

Walker, J. M., Bowen, W. D., Walker, F. O., Matsumoto, R. R., De Costa, B., and Rice, K C. (1990). Sigma receptors: Biology and function. Pharmacological Reviews, 42, 355-402.

Westbrook, G. L., and Mayer, M. L. (1987). Micromolecular concentrations of $\mathrm{Zn}^{2+}$ antagonize NMDA and GABA responses of hippocampal neurons. Nature, 328, 640643.

Westerberg, E., Monaghan, D. T., Cotman, C. W., and Wieloch, T. (1987). Excitatory amino acid receptors and ischemic brain damage in the rat. Neuroscience Letters, $73,119-124$.

White, P. F., Ham, J., Way, W. L., and Trevor, A. J. (1980). Pharmacology of ketamine isomers in surgical patients. Anesthesiology, 52, 231-239.

White, P. F., Schuttler, J., Schafer, A., Stanski, D. R., Horai, Y., and Trevor, A. J. (1985). Comparative pharmacology of ketamine isomers. British Journal of Anaes. thesia, 57, 197-203.

White, P. F., Way, W. L., and Trevor, A. J. (1982). Ketamine-Its pharmacology and therapeutic uses. Anesthesiology, 56, 119-136.

White, W. F., Nadler, J. V., Hamburger, A., Cotman, C. W., and Cummins, J. T. (1977). Glutamate as a transmitter of hippocampal perforant path. Nature, 270, 356-357. 